\title{
Qualitative Economics-A Perspective on Organization and Economic Science
}

\author{
Michael Fast ${ }^{1}$, Woodrow Clark II $^{2}$ \\ ${ }^{1}$ Department of Business and Management, Aalborg University, Aalborg, Denmark \\ ${ }^{2}$ Clark Strategic Partners, Beverly Hills, USA \\ Email: fast@business.aau.dk,wwclark13@gmail.com
}

Received December 21, 2011; revised January 14, 2012; accepted January 23, 2012

\begin{abstract}
Focus in this paper is on building a science of economics, grounded in understanding of organizations and what is beneath the surface of economic structures and activities. As a science Economics should be concerned with its assumptions, logic and lines of arguments, and how to develop theories and formulate ideas of reality. There is a disconnection between a science of economics focuses on structures and universal laws from what is experienced in everyday of life of business activity. The everyday of life of business is processual, dynamic and contradictional. This discussion of how to understand the everyday economic life is the central issue and is discussed from the perspective of interactionism. It is a perspective developed from the Lifeworld philosophical traditions, such as symbolic interactionism and phenomenology, seeking to develop the thinking of economics. The argument is that economics first of all is about two things; it is about interaction and it is about construction. If we are not able to understand and describe how people interact and construct, we cannot develop any theory of economics or understand human dynamics. So there are two issues to reflect upon: the object of thought and the process of thinking, e.g. the ontology and the epistemology.
\end{abstract}

Keywords: Qualitative; Interaction; Process; Organizing; Thinking; Perspective; Epistemology

\section{Introduction}

Economics and organization is human interaction and construction in and of everyday of life. So to develop economics in to a science that can describe and understand human dynamics, the focus has to be on the demands for such a science in relation to its ontology and epistemology.

The dominant and traditional view on economics is that, it is a matter of constructing theories that can explain the laws invisible to the eye and under the surface. This is the tradition that develops during the 19th and 20th centuries when social science was established, with its roots in positivism (e.g. Comte, [1] Durkheim, [2]) and rationalism (e.g. Descartes, [3]) and later on in system theory (e.g. von Bertalanffy [4]). The epistemologycal question here is if the factors and laws are connected, not in relation to reality but to the models and the constructed theoretical universe. There are no empirical arguments for if and in which way reality is constructed as a system or as a mathematical reality. And if it is possible that reality can be explained strictly on numbers, or if there are universal laws which are only assumed by the tradition.

An alternative to those concepts of science comes from the central philosopher in connection with the development of a subjectivistic approach, especially Immanuel Kant (1724-1804). Kant [5] thought that the inner activities of man as conceptualized in the minds of human beings must be brought into focus. Our thoughts are not turned toward the objects, as they are represented or defined in themselves, independent of human intersubjectivity. Science only understands the world in so far as we have shaped it ourselves by forming ideas of it. If therefore the sciences shall have at least an element of truth in their analyses, pronouncements and validity, they must build on the relative necessity ${ }^{1}$, which is maintained by the intersubjective everyday life reality experienced by man. Sciences do not constitute a reference system standing above, abstracted and removed from the world to justify the validity of everyday life. The scientific conceptualization rests on preconditions, which mankind places into science itself, by being a participant in the experiencal world of everyday life. It is not necessary that the single scientist knows everything about the organizing of an experience. Therefore, he does not necessaryily see the viewpoint presupposed by science or the basis of which he works himself. Kant's view of the rela-

\footnotetext{
${ }^{1}$ i.e. the general understanding of man.
} 
tion between science and everyday life throws light on science as a human endeavor in which we are responsible ourselves for its outcomes [5].

In 1935, Husserl criticized a natural science approach in social science, as being a science that had lost its soul. (Social) Science had to a great extent been studying the culture at the terms of nature. That is, natural science had determined the trend of science, also seen in cultural and social sciences. But man has a soul, a life and a history, which disappear completely, if it is studied on the premises of natural science. Husserl was of the opinion that man has to seek his roots to understand the meaning of his life [6]. His phenomenology is the study of consciousness, and he rejects the notion that consciousness or its contents can be fully investigated from a "theoreticcal attitude" using the philosophical assumptions, conceptual categories, and quantitative methods of science. Instead, the study of consciousness should start from the "natural attitude": the relationship of consciousness to the Lifeworld - the world of ordinary, everyday experience. Only from the "natural standpoint" can we do justice to the exploration of consciousness and human experiences [7].

Schutz [8] underlines that from a phenomenological perspective with the observation that social scientists' facts, events and data are of a totally different structure than in the objective approach. The social world is not structureless in its nature. The world has a special meaning and structure of relevance to those people that live, think and act in it. Human beings have pre-chosen and pre-interpreted this world through a set of commonsense constructions of everyday of life reality. Such a construct of the world outlines those topics of thoughts that determine individual's actions, defines the aim for their actions, the means to achieve them, and that are accessible to reach them. This perspective helps people to orientate themselves in their natural and socio-cultural milieu and to become comfortable with in it. The topics of thoughts that are constructed by the social scientist, refers to and are founded upon the topic of thoughts that are constructed by an individual's commonsense thinking as they live their everyday lives among other people. The constructions, therefore that the scientist use, are thereby constructions of a second order, namely constructions of the constructions that are performed by the actors on the social scene. Then the scientist observes these actions and seeks to understand them in relationship with his scientific procedure rules.

If we are looking for what is meaningful in understanding reality we must have concepts of what that reality is. This is the area of ontology and in relation to economics we have to connect the discussion of economic figures, relations, forces, etc. to where they arise and in which way they are meaningful. The only way to do this is to take the departure in the subject and the subject relation to the phenomenon: both the economic actor and the researcher who is trying to understand the subject. We need a moving picture of what the economic actor is and what his realities are, and we need a focus upon how knowledge of this is produced.

In order to develop such a picture of everyday economic interactions we have to focus upon what will be described as "qualitative economics", as a perspective and understanding of economics. Qualitative is seen in the complex construction by the actors of the economic organizing. The roots in this are in the traditions of "Lifeworld" and interactionism. Lifeworld comes from the German die Lebenswelt, with its roots in the 18th Century philosophy of Kant [5], and later on Husserl [9], Heidegger [10], Schutz [11], Gadamer [12], and can also be seen in the tradition of American philosophers' Mead [13] and Blumer [14] from the early to mid-20th Century. The theoretical development from this philosophical tradition is seen in different schools of contemporary social science thought ranging from phenomenology, hermeneutic, ethnomethodology, linguistics and symbolic interactionism. The Lifeworld tradition and its interactionistic theoretical development is an approach to theorizing, describing, understanding and explaining everyday life, and is therefore creating the science of qualitative economics.

The aim of this paper is therefore-through the everyday life tradition-to discuss the central issues and basic concepts in order to understand and develop a qualitative economic perspective.

\section{The Logic of Qualitative Economics-The Object of Thought}

The reality of economics has been investigated and explained in many ways. But the discussion of how to understand the business research, and how the research is done along with the (ontological and epistemological) assumptions lying behind the research and its reality in everyday life, are rarely discussed. Discussions of philosophy in science and methodology are important for understanding reality and theorizing on its applications in everyday life. It is precisely these connections among philosophy of science that theorizing and methodologies arise to capture the reality, which must be in the center of any scientific discussion. Furthermore, openness and a specific discussion of an alternative philosophical approach to the established traditional way of seeing science and reality are necessary. Thinking and reflection are critical in the scientific investigation of reality together with and related to the basic philosophical assumptions. It is only in this connection that we can talk about something being true (e.g. correct) or false.

We will discuss how to understand the very concept of 
organizations and how organizations are constructed and developed. We need to have an understanding of what people are and what they bring to the organizational economic context by interacting with one another and in groups.

When the functionalistic economic theory fails to understand business life, the root to the problem is in the lack of a conceptual discussion on the very understanding and meaning of business activities within the firm. This section focuses on interaction and the firm as a social construction and upon understanding the process of change and development of the firm. The purpose is to discuss a conceptual understanding of the firm as a subjective, interactionistic and processual phenomenon. The discussion focuses upon the way in which actors in their everyday of life create an understanding of business reality and through their actions and interactions construct and change the firm.

\subsection{The Constitution of the "Firm"}

Organisations are created, maintained and developed though everyday human interaction [3]. All business and economic activities are conducted by individuals communicating in an interactive or face-to-face manner, where the relations consist of concrete meetings between members in the firm. The word "Organization"/"Firm" is (only) a concept, which we use to describe a phenomenon. It is a conceptualization of what we believe and do and what we orient our actions toward. Organization is a concept in the same way as the concepts of family, class in school, a football team, an union etc. In other words, organization is a phenomenon that we experience when and where we see more than one person involved in activities over time.

Thus, organization becomes a collective arrangement where people try to give the situation and the activities meanings. In line with Blumer [14] organizations consist of the fitting together of lines of activity-the interlinking of lines of action. Actors mixing, sharing, competing, and cooperating are parts of the interactive process that define groups and organization. And that is why most organizations, by definition, change and move dynamically in space and time.

By fitting together the lines of action and interaction as logically prior in organization, we are discouraged from mistakenly regarding organizations as "things" or simply "solid entities" such as a building or structure. Organizations are not concrete, immutable or even life-like objects that, somehow independent of our conscious intentions or unconscious motives, shape and determine what we do. The technical term for this kind of cognitive error is "reification", an unconscious tendency to forget or be obvious to the role of human agency in creating, sustaining, and transforming social relations [15]. We actively construct our social reality through language, through a process of symbolization by forming words and sentence to describe our experiences as well as our wants and desires. We create our organizational existence and live within it.

The language we share and use constitutes our relationships [7]. An organization should therefore be understood through the actors who by their actions and knowledge create the firm in their everyday pursuit of life. In this the relation between action and knowledge is the central issue of interaction.

The actions exist in a context that is created by the actor through his/her actions. The action is related to the actor's interpretation and understanding of the situation in the context of meanings imparted in the interaction of the phenomenon $[11,13,14,16,17]$. The actor has motives and definitions of the situation that makes the social world into an inner logic, which have rules and lines of action derived from the situation itself. Actions also happen in connection with expectations. When the actors are involved in the society, they expect suitable actions from themselves and from others: They are capable of understanding meanings of action by others and make their own point-of-view on themselves based on the response of other actors. They associate meanings to situations and to other actor's actions and act in relation to their interpretations of these meanings. This can be understood in relation to typifications, formed by the earlier experiences of the actor, which define his/her "thinking-in-future” of others' possible reaction to his/her actions.

The typifications that the actor uses in a situation are dependent on his/her knowledge in everyday life that is, "the-stock-of-knowledge" and "the generalized other" as Blumer [14] described the phenomenon. These typifications give the individual a frame of reference that the actor can use to create actions and make sense of others' actions. See Blumer's notion of "reflections" for example. Typifications are thereby expectations to others actions containing symbols in relation to community and collective interpretations.

This social reality is pre-defined in the language by which we are socialized. The language gives us categories that both define and emphasize our experiences. The language spoken and dialogue among actors within an organization can be seen as communication of meanings and actions. But such language-usage is also a means to create a new understanding, changes in meanings and a new worldview. Language is the base line from which we understand and can interpret knowledge. Thus, knowledge, as expressed in language-usage, can thereby be understood as moving pictures of reality: experiences and information are produced through actions and transformed (by interpretation and retrospection) to the know- 
ledge that the actor's experiences are useful and relevant.

The world with which the actor is confronted is composed of experiences which the process of consciousness will develop or simplify toward different paths (or structures) and then transformed into actions (again). The actor uses and develops a scheme for interpretation to connect episodes of social action in a sensible way. A "scheme" should be understood as active information seeking pictures that accept information and orient actions continuously $[18,19]$. The action-knowledge process gives an understanding of the way in which people think, act, reflect and interact. Simultaneously it shows that the actors are engaged in their environment by means of interpretation and orientation with one another. Through this process they give define and give meaning.

The focus in the understanding of the organization is upon the way organizational members interpret their organizational world, which is nothing else than a special sphere of the individual's Lifeworld. Lifeworld refers to the fact that in any real-life experience there is something that is given in advance or something that exits in advance and thus, taken for granted. This taken-for-granted world includes our everyday life and whatever prejudices and typical interpretations we may derive from it. Acting as a member of an organization, therefore, does not differ essentially from acting as an individual, for "whether we happen to act alone or, cooperating with others, engage in common pursuits, the things and objects with which we are confronted as well as our plans and designs, finally the world as a whole, appears to us in the light of beliefs, opinions, conceptions, certainties, etc., that prevail in the community to which we belong" [17]. The important characteristic of this experience in any organization becomes the typical form of everyday life. Or as described by Schutz [20]: The individuals commonsense knowledge of the world is a system of constructs of its typicality. In social interaction, the role of typification is important and can be expected to vary according to the nature of the relationship.

\section{2. "Environment"}

The environment is not an objective fact but something members of the work shop produce or rather co-produce as a consequence of their acts [21]. The enacted environment is orderly, material, social construction that is subject to multiple interpretations [22]. The existence of the objects in the environment is not questioned, but their meanings are. The traditionally distinction as well as the conception of environments and organisations embedded in organization literature is seriously questioned by Weick $[18,22]$. We think Weick is right stating that when concepts like organization and environment are treated as entities they start working as pre-judgment [12] or self- fulfilling prophesy. In other words when researchers make a clear-cut between an organisations and its environment they automatically or unconsciously starts looking for confirmation on these assumptions. In Weick's perspective even an analyses of the environment becomes an act affecting and shaping the environment. The basic assumption is that reality is seen as a social construction [18]. Members, and especially managers, of organisations enact the environment by constructing, rearranging, singling out and demolishing [18] phenomenon in their surroundings. Since the construction of reality is a social process the manager is not alone when reality is constructed. The manager is obviously interacting with others and during these interactions reality is constructed. Clearly an enacted environment is not synonymous with a perceived environment [18] but it is also clear that the perception of reality must somehow be influenced by the reality being socially constructed by members of an organization. The social construction of reality work as a self-fulfilling prophecy making members of an organization look for and find what they expect to find in the environment.

The actors in their "environment" construct reality and knowledge. It is precisely because knowledge is a relation to and has an orientation towards the "environment" through action, that the environment itself can be defined as the experiential space and as the interpretation space.

The experiential space is what is close and concrete, where the actors travel and interact. This can be seen in the consciousness of human beings in "the natural attitude" first of all being interested in that part of the actor's everyday of life world that is in his reach and that in time and space are centered around him/her [8]. The place where the body occupies the world, the actual here, is the point from which one orientates oneself in the space. In relation to this place, one organizes elements in the environment. Similarly, the actual now is the origin of all the time perspectives under which one organizes events in the world as before and after, and so on. This experiential space is experienced by the actor as the core of reality, as the world within his reach. It is the reality in which we are all engaged.

The interpretation space can be seen as the reality beyond the actor's knowledge (e.g. through stories, tales) where something which the actor relates to, but which is not centered around his or her everyday of life, e.g. not in time. In relation to this, we can see the distinction that Weick [23] talks about when he says, that humans live in two worlds - the world of events and things (or the territory) and the world of words about events and things (or the map). In this, the process of abstraction is the process that enables people to symbolize [14], and is described as "the continuous activity of selecting, omitting, and organizing, the details of reality so that we ex- 
perience the world as patterned and coherent”. This process becomes necessary but inherently is inaccurate, because the world changes continuously and no two events are the same. The world becomes stable only as people ignore differences and attend to similarities. In a social constructed world, the map creates the territory. Labels of the territory prefigure self-confirming perspectives and action.

This perspective also means that the development of knowledge has its start in the actor's existing knowledge. Or as Weick [23] put it: it takes a map to make a map because one points out differences that are mapped into the other one. To find a difference, one needs a compareson and it is map like artifacts which provide such comparisons.

The development can be seen in relation to the actor's everyday experiences with his attempt to orient him/herself and to solve problems. When the actors act in their experiential space, they thus widen their understanding of reality by interpreting and relating themselves to the result of the actions. Development of knowledge involves interpretation and retrospection whereby the actors create their experiential space: Reality is what one sees; hence it changes every time the actor constructs a new concept or a picture of connections. Development of knowledge thus demands that the actor reflects and relate to an understanding of the situation and the experiential space.

The essence is in the idea that we all develop knowledge through actions and that actions are the means by which we engage ourselves in the reality; our actions construct and keep us in touch with the world $[24,25]$. The action-knowledge discussion is built upon the assumption that we only have a reality in force of that we are engaged in it: reality is socially constructed. This does not imply that people are in full control over the process of constructing the reality or that they have possibilities to change it basically, because they do not act alone and because it is an on-going process.

It is necessary now to take the discussion of actors, actions and knowledge, and develop an understanding of the way in which people are orientated toward each other and in which way the organizational reality actually becomes a reality.

\subsection{Interaction and Knowledge}

Interaction is symbolic in the sense that actors respond to the actions of others, not for some inherent quality in them, but for the significance and meanings imputed to them by the actors. Meanings shared in this way, in an intersubjective way, form the basis for human social organization [26]. People learn symbols through communication (interaction) with other people, and therefore many symbols can be thought of as common or shared meanings and values [27]. This mutually shared character of the meanings gives them intersubjectivity and stresses that it is interaction and intersubjectivity that constitute the firm as a reality for the actors. Interaction in this relation should be understood as a complete sequence of interaction, as a process of interaction.

The central point in this is the time perspective and the dependency of the context and the acts: It is the actions by the actor and the process of interaction that give and make the firm over time. The "firm" therefore both has a past (the experiences of the actors) and a present (the actors interpretations and pictures) and a future in relations to the actors fantasies of the future and orientations. The processes related to interaction are presented in the figure below.

Figure 1 outlines interaction between the actors in the firm. It is a process of knowledge development, which occurs through the process of interaction in an experiential space. It is intersubjective and can be seen as a moving picture that defines what the actors' experience as important and real. Thus, knowledge has an impact on future actions and is central for an understanding of the actors' orientation and the organizational actions. The actors' act in relation to the picture and definition they have of the experiential space and the situation. Each action means possibilities for experiences and information, and for strengths or weaknesses in interpretation of connections in the situation. In every situation there is the possibility of several different interpretations. This means that changes in the experiential space create ambiguity and the actors are tempted to use previous successful actions and interpretations-the existing picture of reality.

\subsection{Organizing-Fitting Together of Lines of Activities and Actions}

Through the processes of interaction, the actors construct

Interpretation Space

(construction but not everyday life-space but not time)

Experiential Space

(everyday life construction-time and space)

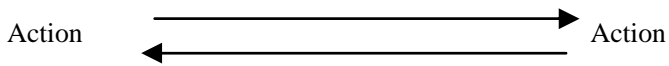

(Me)

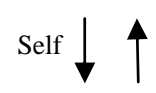

Interaction process

Language

(Me)

Knowledge

(I)

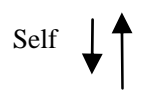

Knowledge

(I)

Fitting together of lines of activities and actions

Figure 1. Knowledge and interaction. 
some results: the interaction means organizing and creation of the firm, and the actors create a moving picture of and a relation to the experiential space. The actors create intersubjective moving pictures of the reality, which is an organizational paradigm.

The actors create over time that thing we define as the "firm". The processes that occur can be understood as organizing, which not only focuses upon action and interaction but also on creation of meanings of reality and intersubjectivity. Essentially, the firm can be understood as overlapping interactions. The actors create the firm through interactions, but "it" has also an influence upon them through their interpretation of "it". This dialectical perspective appears from the view that the firm only exists through the interactions between the actors and thus is viewed as a corollary of these interactions. Simultaneously, the organization is historically to the individual member: The individual enters into an already existing organizational everyday of life, which sets the institutional parameters for his self-development. Self and organization thus develop together and because of each other in a dialectical process of mutual transformation [13,26,28-30].

The actors have to live with and exist with uncertainty and ambiguity. In other words, the way in which the actors handle themselves is in itself uncertain and exposed to many different interpretations and understandings. To reach security, the actors attempt to organize their activities. Organizing means assembling the actions and should be seen in relation to interpretation and understanding by the actors. The actors form their actions so as obtain information and experiences that give meanings to the organizational world. This is organized by the actors in an attempt to construct an understanding. In the organizing the dependent actions are oriented towards removing contradictions and uncertainty: the actors seek to define and make sense in their situation, and thus they both create the firm and the experiential space. Organizing is to be seen as a social, meaning-making process where order and disorder are in constant tension with one another, and where unpredictability is shaped and "managed". The raw materials of organizing are people, their beliefs, actions and their shared meanings that are in constant motion [31].

There is a similarity between the phenomenological meanings of the practical activity of organizing and theorizing - the act of sense-making is in fact the central feature of both. Theorizing is most fundamentally an activity of making systematic as well as simplified sense of complex phenomena that often defy understanding by everyday, common-sense means. Theorizing might also be seen as a means by which people in organizations make their own and other's actions intelligible by reflective observations of organizing processes; through these processes novel meanings are created and possibilities for action are revealed. Theorizing becomes an act of organizing, first, when it is a cooperative activity shared in by several or even all of the actors in an organizational setting; and second, when its purpose is to reveal hidden or novel possibilities for acting cooperatively. Organizing is cooperative theorizing and vice versa [15]. In short, the firm is a social construction and a collective phenomenon.

Interaction between actors in a situation allows for many different interpretations whereby the actors are facing multiple realities. The interaction between different opinions means that new conceptions may arise. The reality is seen differently which produces changes. Brown states that the organizational change could be seen as an analogy with scientific change: “... most of what goes on in organizations, involves practical as well as formal knowledge. That is, the relevant knowledge is often a matter of application, such as how to employ the official procedures and when to invoke the formal description of those procedures, rather than abstract knowledge of the formal procedures themselves. Paradigms, in other words, may be understood not only as formal rules of thought, but also as rhetoric and practices in use” [16].

Bartunek [19] talks about an organizational paradigm as interpretive schemes, which describes the cognitive schemata that map our experience of the world through identifying both its relevant aspects and how we are to understand them. Interpretive schemes operate as shared, fundamental (though often implicit) assumptions about why events happen as they do and how people are to act in different situations.

The structures of meaning arises in and is institutionalized through the action of human beings, our own and those of our fellow men, and those of our contemporaries and our predecessors. All objects of culture (tools, symbols, language systems, social institutions, etc.) point back, through their origin and meaning, to the activities of human subjects. Intersubjectivity, therefore, can be seen as a common subjective state or as a dimension of consciousness that is common to a certain social group who mutually affects each other. The social connections are rendered possible through the intersubjectivity such as through a mutual understanding of common rules that are, however, experienced subjectively. Intersubjectivity refers to the fact that different groups may interpret and experience the world in the same way that is necessary at a certain level and in some contexts out of regard for collective tasks.

Human behavior is part of a social relationship, when people connect a meaning to the behavior, and other people apprehend it as meaningful. Subjective meanings are essential to the interaction, both to the acting person who has a purpose with his action and to others who shall 
interpret that action and react in correspondence with the interpretation [14]. The basis for intersubjectivity is the social origin of knowledge or the social inheritance in which the acting persons are socialized to collectively typify repeated social events as external, objective events (which shall be seen in relation to structures of meaning). However, in consciousness such a typification is experienced as subjective reality.

Essence of all this is that the meaning people create in their everyday reality gives the understanding of why people are like they are which can be seen in their interaction and intersubjectivity, including their common interpretations, expectations and typifications. As long as organizational actors act as typical members, they tend to take the official system of typification for granted as well as the accompanying set of recipes that help them define their situation in an organizationally approved way. The emergence of other, non-organizationally defined typifying schemes results from the breaking down of the taken-for-granted world when the actors enter into faceto-face relationships.

\section{Connections of Everyday of Business Life-The Process of Thinking}

Kant [5] thought that the problem with all classical objective metaphysics was that it forgot to investigate the meaning and cognitive reach of its own concepts.

Kant's first attempt, in creating an understanding of the relation between man and reality, was to establish a synthesis of two ways of thinking which were mutually contradictory: the Cartesian dualism between soul and body, as well as Hume's resolution of self-conceit. i.e. Descartes's distinction between thought and extension: thinking has its own principles of movement, and the thing follows other principles. And Hume's view, that the relationship of man to the world is based on natural belief and faith - a practical relationship that cannot be explained theoretically as cognition and through the ego. Kant was of the opinion that all cognition starts with the experience, and that knowledge was a synthesis of experiences and concepts: without sensing we cannot be aware of any objects (the empirical cognition); without understanding we cannot form an opinion of the object (the a priori cognition): "There can be no doubt that all our knowledge begins with experience. For how should our faculty of knowledge be awakened into action did not objects affecting our senses partly of themselves produce representations, partly arouse the activity of our understanding to compare these representations, and, by combining or separating them, work up the raw material of the sensible impressions into that knowledge of objects which is entitled experience? In the order of time, therefore, we have no knowledge antecedent to experience, and with experience all our knowledge begins” [5].

However, there are limits to knowledge. Kant distinguishes between the phenomena (the world of phenomena) and reality (the noumenal world): We cannot apprehend the mysterious substance of the thing, what he called "das Ding an Sich" (the-thing-in-itself). If we try to go outside the world of phenomena, i.e. if we wish to use the concepts outside the limits of the comprehensible world, it will lead to paradoxes, fallacies and pure selfcontradictions. Kant argued that the traditional metaphysical arguments about the soul, immortality, God and the free will all exceed the limits of reason. Reason can only be used legitimately in the practical sphere, i.e. if we try to acquire knowledge of the world. If we cannot reach das Ding an Sich, then we must be satisfied with "das Ding für Uns" (the things as they presents themselves to $\mathrm{us}^{2}$ ).

This is the question that we have to raise when we are studying the field of economics: What are the things, who are the actors, and in which way do I understand?

The primary goal of the social sciences is to obtain organized knowledge of social reality. Schutz understands social reality as the sum total of objects and occurrences within the social cultural world as experienced by the "common-sense" thinking of men living their daily lives among their fellow-men, connected with them in manifold relations of interaction [32]. It is a world of cultural objects and social institutions in which we are born, in which we have to find our bearings and to come to terms with. Seen from outside, we experience the world we live in as a world which is both nature and of culture, not as a private world, but as an intersubjective world. This means that it is a world common to all of us, either actually given or potentially accessible to everyone; and this involves intercommunication and languages. It is in this intersubjective world that action shall be understood.

In this everyday Lifeworld the actors use "common sense knowledge”, as kind of knowledge held by all socialized people. The concept refers to the knowledge on the social reality held by the actors in consequence of the fact that they live in and are part of this reality. The reality experienced by the actors as a "given" reality; i.e. it is experienced as an organized reality "out there”. It has an independent existence, taking place independently of the individual. However, at the same time this reality has to be interpreted and made meaningful by each individual through his experiences-we experience reality through our common sense knowledge, and this knowledge is a practical knowledge of how we conduct our everyday lives.

All our knowledge about the world involves construc-

${ }^{2}$ cf. also Husserl's concept of intentionality. 
tions, i.e. a set of abstractions, generalizations, formalisms and idealizations which are specific for the organ izational level of thoughts in question [8]. Such things as pure and simple facts do not exist.

According to Schutz [8] social science must deal with the behavior of man and common sense interpretation in the social reality, based on an analysis of the entire system of projects and motives, of relevance's and structures. Such an analysis refers necessarily to the subjective viewpoint, i.e. to interpretation of the action and its surroundings from the viewpoint of the actor. Any social science that wishes to understand "social reality" must adopt this principle. This means that you always can and for certain purposes must refer to the activities of the subjects in the social world and their interpretation through the actors in project systems, available means, motives, relevance's, etc.

To be able to understand the social reality and handle the subjective views, science must construct its own objects of thought, which replace the objects of common sense thinking. This approach allows for an understanding of research work on models of parts of the social world, where typical and classified events are dealt within the specific field in which the research worker is interested. The model consists of viewing the typical interactions between human beings, and to analyze this typical pattern of interaction as regards its meaning to the character types of the actors who presumably created them. The social research worker must develop methodological procedures to acquire objective and verifiable knowledge about a subjective structure of meaning.

In the sphere of theoretical thinking, the research worker "puts in brackets" his physical existence and thus also his body and its system of orientation, of which his body is the center and the source [8]. The research worker is interested in problems and solutions, which in themselves are valid, to anybody, everywhere, at any time, anywhere and whenever certain conditions, from which he starts, are present. The "jump” in theoretical thinking involves the decision of the individual to suspend his subjective viewpoint. And this very fact shows that it is not the undivided self, but only a partial self, a role player, a "Me", i.e. the theorist, who acts in scientific thinking. The features of the epoché, which is special for the scientific attitude, can be summarized through the following. In this epoché the following is put in brackets: 1) The thinking subjectivity as man among fellow men, including his bodily existence as psychophysical human being in the world; 2) The system of orientation through which the everyday Lifeworld is grouped in zones within actual, restorable, achievable reach, etc.; 3) The fundamental anxiety and the system of practical relevances, which originate from it [8].

The system of relevance's, reigning within the prov- ince of scientific contemplation, arises in the random act of the research worker, when he chooses the object of his further exploration, i.e. through the formulation of the existing problem. Thus, the more or less anticipated solution to this problem becomes the summit of the scientific activity. On the other hand, the mere formulations of the problem, the sections or the elements of the world, which are topical or may be connected to it as relevant concerning the present case, are determined at once. After that this limitation of the relevant field will pilot the investigation.

The difference between common sense structures and scientific structures of patterns of interaction is small. Common sense structures are created on the basis of a "Here" in the world. The wide-awake human being in the natural attitude is first of all interested in the sector of his everyday Lifeworld, which is within his reach, and which in time and space is centered around him. The place that my body occupies in the world, my topical Here, is the basis from which I orient in the space. In a similar way my topical "Now" is the origin of all the time perspectives under which I organize events in the world, like before and after, past and future, presence and order, etc. [8] I always have a Here and a Now from which I orient and which determines the reciprocity of the assumed perspectives and which takes a stock of socially derived and socially recognized knowledge for granted. The participant in the pattern of interaction, led by the idealization of the reciprocity of the motives, assumes that his own motives are joined with those of his partner, while only the manifest fragments of the actions of the actors are available to the observer. But both of them, the participant and the observer, create their common sense structures in relation to their biographic situation.

The research worker has no Here in the social world which he is interested in investigating. He therefore does not organize this world around himself as a center. He can never participate as one of the acting actors in a pattern of interaction with one of the actors at the social stage without, at least for some time, to leave his scientific attitude. His contact is determined by his system of relevance, which serves as schemes for his selection and interpretation of the scientific attitude which is temporarily given up to be resumed later. The research worker observes, assuming the scientific attitude, the pattern of interaction of human beings or their results, in so far as they are available to become observations and open to his interpretation. But he must interpret these patterns of interaction in their own subjective structure of meaning, unless he gives up any hope of understanding "social reality" on its own merits and within its own situational context.

The problematic that Schutz brings up here and the understanding that one may reach of the subjective 
knowledge of another person, can be expressed in the following way. The whole stock of my experience (Erfahrungsvorrat) of another from within the natural attitude consists of my own lived experiences (Erlebnisse) of his body, of his behavior, of the course of his action, and of the artifacts he has produced. My lived experiences of another's acts consist in my perceptions of his body in motion. However, as I am always interpreting these perceptions as "body of another", I am always interpreting them as something having an implicit reference to "consciousness of another". Thus the bodily movements are perceived not only as physical events but also as a sign that the other person is having certain lived experiences, which he is expressing through those movements. My intentional gaze is directed right through my perceptions of his bodily movements to his lived experiences lying behind them and signified by them. The signitive relation is essential to this mode of apprehendding another's lived experiences. Of course he himself may be aware of these experiences, single them out, and give them his own intended meaning. His observed bodily movements become then for me, not only a sign of his lived experiences as such, but of those to which he attaches an intended meaning. The signitive experience (Erfahrung) of the world, like all other experience in the Here and Now, is coherently organized and is thus "ready at hand" [11].

The point is how two "streams of consciousness" get in touch with each other, and how they understand each other. Schutz expresses it quite simply, when he talks about the connection, as: the phenomenon to "grow old together"; to understand the inner time (durée) of each other. In fact, we can each understand all others by imagining the intentional acts of the other, when they happen. For example, when someone talks to me, I am aware-not only of the words-but also of the voice. I interpret these acts of communication in the same way as I always interpret my own lived experiences. But my eyes go directly through external symptoms to the internal man of the person talking. No matter which context of meaning I throw light on, when I experience these exterior indications, its validity is linked with a corresponding context of meaning in the mind of the other person. The last context must be where his present, lived experiences are constructed steps by step [11].

The simultaneousness of our two streams of consciousness does not necessarily mean that we understand the same experiences in identical ways. My lived experiences of you are, like the surroundings that I describe to you, marked by my own subjective Here and Now, and not by yours. But I assume that we both refer to the same object that thus transcends the subjective experiences of both of us. But at the same time not all your lived experiences are open to me. Your stream of lived experiences is also a continuum, but where I can catch detached segments of it. If I could become aware of all your experiences, you and I would be the same person. Hence, the very nature of human beings is that they do not have exactly the same interpretation of experiences; and therefore are different. It is precisely this human diversity that distinguishes humans from other life forms yet creates conflict and turmoil within societies and between them.

We also differ in other ways; how much of the lived experiences of the other we are aware of; and that I, when I become aware of the lived experiences of the other, arrange that which I see within my own meaning context. And in the meantime the other has arranged them in his way. But one thing is clear: This is that everything I know about your conscious life is really based on my knowledge of my own lived experiences. My lived experiences of you are constituted in simultaneity or quasi-simultaneity with your lived experiences, to which they are intentionally related. It is only because of this that, when I look backwards, I am able to synchronize my past experiences of you with yours past experiences [11]. My own stream of consciousness is given to me continuously and in all its perfection, but that of the other person is given to me in discontinuous segments and never in its perfection and exclusively in "interpreted perspectives". This also means that our knowledge about the consciousness of other persons can always be exposed to doubt, while our own knowledge about our own consciousness, based as it is on immanent acts, is in principle always indubitable. In the natural attitude we understand the world by interpreting our own lived experiences of it. The concept of understanding the Other is therefore the concept: "Our interpretation of our lived experiences of our fellow human beings as such". The fact that the You confront me as a fellow human being and not a shadow on a screen-in other words that the Others duration and consciousness-is something that I discover through interpretation of my own lived experiences of him. In this way the very cognition of a "You" also means that we enter into the field of intersubjectivity, and that the world is experienced by the individual as a social world.

So in this discussion of how to understand phenomena and meaning we have to focus on the central dimension: language.

\section{Language as Science}

Connected to Symbolic Interactionism and Phenomenology is Chomsky's [33] theory of languages such that natural language is common "to discover 'the semantic and syntactic rules or conventions (that determine) the meanings of the sentences of a language', and more im- 
portant, to discover the principles of universal grammar (UG) that lie beyond particular rules or conventions". Chomsky's "primary purpose is to give some idea of the kinds of principles and the degree of complexity of structure that it seems plausible to assign to the language faculty as a species-specific, genetically determined property" [33]. He does this by distinguishing between "surface" and "deep" structures.

Chomsky describes the Surface Structure as the basic everyday words and sentences we use to communicate. On the Surface, we understand each other, or think that we do, and proceed to communicate and behave based on those sets of assumptions. At the Surface level, we can form "various components of the base interact to general initial phrase markers, and the transformational component converts an initial phrase marker, step by step, into a phonologically represented sentence with its phrase marker" [33]. In short, we can take everyday discussions and mark the sentences into a theoretical form for further detail and analysis. This process leads to the transformational derivation which is "The sequence of phrase markers generated in this way...” to form sentences [33]. From this process we have the syntax of a language.

The basic terms are structure and deep structure which refer "to non-superficial aspects of surface structure, the rules that generate surface structures, the abstract level of initial phrase markers, the principles that govern the organization of grammar and that relate surface structure to semantic representations, and so on" [33]. The Deep Structures are the semantics that give meanings to the sentence and words of the Surface Structures. Figure 2 illustrates the relationship between Surface and Deep Structures. Transformational relations or rules connect the two structures.

"We use language against a background of shared beliefs about things and within the framework of a system of social institutions" [34]. Transformations are rules (shows the occurrence of a word corresponding to a yesno question), which "map phrase markers into (other)

\begin{tabular}{|c|c|c|}
\hline $\mathrm{T}$ & \multicolumn{2}{|l|}{ Surface Structures (Phonetic-Everyday Language) } \\
\hline $\mathrm{R}$ & <---------------Language Discourse -----------------> & \\
\hline A & Universal Grammar & $\wedge$ \\
\hline $\mathrm{N}$ & $\overline{\text { Syntax }}$ & | \\
\hline S & Data (methodology: interactive/qualitative) & \\
\hline $\mathrm{F}$ & Empirical (actual use of language) & 1 \\
\hline $\mathrm{O}$ & & \\
\hline $\mathrm{R}$ & Deep Structures (Semantics - & i \\
\hline M & meaning to words/sentences) & | \\
\hline A & & | \\
\hline $\mathrm{T}$ & Generative & i \\
\hline I & Phrase Markers & | \\
\hline $\mathrm{O}$ & Rules (principles that form language): & i \\
\hline $\mathrm{N}$ & Appropriateness etc. & | \\
\hline S & Lexicon & $\mathrm{v}$ \\
\hline
\end{tabular}

Figure 2. Linguistic transformation theory (N. Chomsky, 1975). phrase markers" [33]. Transformation component is "One component of the syntax of a language consists of such transformations with whatever structure (say, ordering) is imposed on this set" [33]. For the transformation component to function in generating sentence structures, must have some class of "initial phrase markers" [33]. The concept of Universal Grammar indicates that all languages contain the components in Figure 2. In other words, the Transformational Theory can apply to all languages. "The study of language use must be concerned with the place of language in a system of cognitive structures embodying pragmatic competence, as well as structures that relate to matters of fact and belief” [34].

A number of useful concepts can be borrowed from linguistic theory for the understanding of economics. The basic premise of linguistic theory is that language has its own order. The use of grammar to connect ideas requires the definition and meanings of words, phrases and sentences to be understood. To that requires the scientific method which consists of hypotheses, observation, data collection and analyses with the ability to replicate experiments (in this case language) in order to validate the hypotheses. Linguistic theory does this through the examples of deep and surface structures, which need to be understood through the interactions of transformational rules. The application of linguistic theory and science to economics can be done with a focus in four areas.

First, as noted, language distinguishes human beings from all other forms of life. Humans do have complicated language and therefore communication systems that allow them to send messages, symbolize, create, and build on a body of knowledge. Human language is composed of complicated sets of symbols that when used interactively allow messages to be transmitted. Second, linguistic theory argues that language is divided into two components: surface and deep structures. The surface structures are those symbols that people use in their everyday life to speak and write. The surface structures are the part of the grammar that cultures devise in order to record their history, communicate, and transact business. The deep structures are an entirely different phenomenon. Language has meaning attached to words and combinations of words (sentences) that are not expressed in the communication act itself. Furthermore, many of the deep structures are not defined in dictionaries or other guides to the language. In short, deep structures constitute the real core and understanding of any language and therefore of any culture and people's actions. Third, individuals learn surface structures (speaking and dialogue of a language) throughout their lives. Some of aspects of language can be taught. However, empirical studies show people understand or learn the deep structures (grammar and syntax) at an early age.

The qualitative perspective focuses on understanding 
of the meaning and definitions behind the interactive dynamics of human change within society. Qualitative methods and language therefore become crucial for describing, understanding, and perhaps predicting the human condition. Quantitative methods on the other hand do not provide an adequate framework or even set of tools to understand the creativity of innovation and its adaptation in everyday business life. Moustakas [35], in discussing qualitative methods, talks about the common qualities and bonds of human science research as being: 1) Recognizing the value of qualitative designs and methodologies, studies of human experiences that are not approachable through quantitative approaches; 2) Focusing on the wholeness of experience rather than solely on its objects or parts; 3) Searching for meanings and essences of experience rather than measurements and explanations; 4) Obtaining descriptions of experience through first-person accounts in informal and formal conversations and interviews; 5) Regarding the data of experience as imperative in understanding human behavior and as evidence for scientific investigations; 6) Formulating questions and problems that reflect the interest, involvement, and personal commitment of the researcher; 7) Viewing experience and behavior as an integrated and inseparable relationship of subject and object and of parts and whole.

The qualitative perspective is strongly humanistic, with focus upon the understanding of the human being, the human condition and of science. An empirical science has to respect the nature of the empirical world that is its objects of study, and the empirical world is understood as the natural world created by group life and conduct. To study it is to involve and interact with the actual group of actors, to understand how they carry on in their lives-social life appears in their natural environmentin their everyday of life. In seeing the organization as an organization of actions, interactionism seeks to understand the way in which the actors define, interpret, and meet the situations at their respective Here and Now. The linking together of this knowledge of the concatenated actions yields a picture of the organized complex.

In a qualitative perspective some general demands to scientific constructions, is needed. The discussion of science and its demands on the structure of models for the understanding of the social or business reality can be categorized in four principles:

1) The demand for logical consistency. The system of typical structures drawn up by the research worker must be established with the largest extent of clearness and precision in the frame of concepts implicated and must be fully compatible with the principles of formal logic. The fulfillment of this demand guarantees the objective validity of the objects of thought constructed by the research worker, and their strictly logical character is one of the most essential features with which scientific objects of thought differ from the objects of thought constructed by common sense thinking in everyday life which they are to replace. In other words: A logically connected system implies that the means-goal relations together with the system of constant motives and the system of life plans must be constructed in such a way that: 1) it is and remains accepted by the principles of formal logic; 2) all its elements are drafted in full clearness and precision; 3 ) it only contains scientifically verifiable assumptions which must be totally accepted by all our scientific knowledge [8].

2) The demand for subjective interpretation. The researcher must, to explain human action, ask which model can be constructed by an individual consciousness and which typical content must be ascribed to it, in order to explain the observed facts as a result of such an activeity of consciousness in an understandable relation. The acceptance of this demand guarantees the possibility of referring all kind of human action or its result to the subjective meaning that such an action or its result has to the actor [8].

3) The demand for adequacy. Any expression in a scientific model referring to human action must be constructed in such a way that a human act carried out in the Lifeworld by an individual actor in the way which is indicated by the typical structure is rational and understandable to the actor himself as well as to his fellow men in the common sense interpretation of everyday life. The demand for adequacy is of the greatest importance to social scientific methodology. Adequacy makes it possible for social science to refer to events in the Lifeworld at all. The interpretation of the researcher of any human act and situation could be the same as that of the actor or his partner. Accordance with this principle therefore guarantees the consistency of the data of the researcher with data in the common sense experience of everyday business reality [8].

4) The demand for ethics. Ethics must be applied to research in everyday business life. Because the interacttion between the researcher and the subjects is intense and often revealing, it is important that the results of the work reflect the concerns and well-being of those who provided the data. Dire consequences could come to people if certain business secrets (as in the case presented in chapter 9 and 10 below regarding intellectual property of commercialized inventions) or strategies are revealed. Everyday business life has numerous hazards attached to it; the work of the researcher should not be one of them. In the end, the researcher should be able to contribute and enhance the wellbeing of the everyday business activity under study. And this is precisely the purpose of action research: to contribute to the business situation through interaction [3]. 


\section{Summary and Conclusions}

The business actions of people, groups and their networks and organizations are about people interacting in everyday of life, trying to construct the future and making sense of the present. In the science of economics we have to focus upon that, but the dimension in this is to create theories that make a difference.

Weick [23] talks about that and end up with some qualities as possible properties of such moving theories: 1) Analysis is focused on what people do; 2) Context of action is preserved, and context-free depiction of elements is minimized; 3) Holistic awareness is attributed to the actor; 4) Emotions are seen to structure and restructure activity; 5) Interruptions are described in detail with careful attention to what people were doing before the interruption, what became salient during the interruption, and what happen during resumption of activity; 6) Activity is treated as the context within which reflection occurs, and reflection is not separate from, behind, and before action; 7) Artifacts and entities are portrayed in terms of their use, meaning, situated character, and embedding in tasks rather than in terms of their measurable properties; 8) Knowledge is seen to originate from practical activity rather than from detached deductive theorizing or detached inductive empiricism; 9) Time urgency rather than indifference to time is treated as part of the context; 10) The imagery of fusion is commonplace, reflecting that activity takes place prior to conceptualizing and theorizing; and 11) Detachment from a prob- lem and resort to general abstract tools to solve it is viewed as a last resort and a derivative means of coping rather than as the first and primary means of coping (whatever else people may be, they are not lay social scientists).

In Weick's discussion of theorizing and understanding, he points to important issues in science and theorizing: What is interesting science in terms of saying something meaningful about reality, and what is not? What is important to people in their search for understanding of their reality and to organize their everyday of life, and what is not important?

In the discussion of the "firm" and its constant economical and organizational changes, it is important to have an understanding of both organizing and time and space as a subjective and intersubjective phenomenon. The process of organizational activities and actions comes from interpretation and understanding of the situation by those actors involved in the actions. It is thereby a discussion of interaction processes and the way in which the actors interpret the processes, and how the interpretations effect changes in the organizational development of the firm.

The development of the firm is a complex phenomenon, but also an everyday of life reality for people and thus very simple on another level of understanding. It is not something one experiences as abstract. Individuals are engaged in and related to the firm and are thinking about it in very concrete ways. Firms are unique phenomena, simply by the reason that people are unique. To understand a firm - an organization - we have to treat it as subjective and qualitative phenomena. In this, the central issue in understanding the firm is an understanding of the actors subjectivity and intersubjectivity with their motives and intentions in their everyday business life. People understand themselves retrospectively and act accordingly, but additionally they are thinking-in-future: What are the projects they are thinking upon? In which way do they try to realize them? And how do the projects change through the process of action and interaction? People construct their organizational reality through actions in everyday life and they build paradigms in order to orient themselves to their own reality. We have to relate ourselves to this discussion in economics if it is the empirical reality and not the theoretical "reality" in which we are interested. In other words, understanding of the social construction of people's organizational life and activities is the context of their everyday business life within the firm.

\section{REFERENCES}

[1] A. Comte, “Om Positivismen,” Korpen, Göteborg, 1991.

[2] Durkheim, “Sociologins Metodregler,” Korpen, Göteborg, 1991.

[3] W. Woodrow II and M. Fast, "Qualitative Economics: Towards a Science of Economics,” Coxmoor Publishing Company, Chipping Norton, 2008.

[4] L. von Bertalanffy, “General System Theory,” Allen Lane, The Penguin Press, London, 1971.

[5] I. Kant, “Critique of Pure Reason,” Macmillan, Hong Kong, 1929.

[6] C. Bjurwill, “Fenomenologi,” Studentlitteratur, Lund, 1995.

[7] J. D. White, "Phenomenology and Organizational Development,” Administrative Science Quaterly, Vol. 28, 1990, pp. 331-496.

[8] A. Schutz, "Hverdagslivets Sociologi," Hans Reitzel, København, 1973.

[9] E. Husserl, “Ideas,” Macmillan, New York, 1962.

[10] M. Heidegger, "Being and Time,” Blackwell, Oxford, 1992.

[11] A. Schutz, "The Phenomenology of the Social World," Heinemann Educational Books, London, 1972.

[12] H.-G. Gadamer, “Truth and Method,” Sheed \& Ward, London, 1993.

[13] G. H. Mead, "Mind, Self, \& Society-From the Standpoint of a Social Behaviorist,” The University of Chicago Press, Chicago, 1962. 
[14] H. Blumer, "Symbolic Interaction-Perspective and Method,” Prentice-Hall, Englewood Cliffs, 1969.

[15] R. P. Hummel, "Applied Phenomenology and Organization,” Administrative Science Quaterly, Vol. 14, No. 1, 1990, pp. 10-17.

[16] R. H. Brown, "Bureaucracy as Praxis: Towards a Political Phenomenology of Formal Organizations," Administrative Science Quarterly, Vol. 23, No. 3, 1978, pp. 365-382. doi:10.2307/2392415

[17] R. Jehenson, "A Phenomenological Approach to the Study of the Formal Organization,” In: G. Psathas, Ed., Phenomenological Sociology-Issues and Applications, John Wiley \& Sons, New York, 1978.

[18] K. E. Weick, “The Social Psychology of Organizing,” Addison-Wesley Inc., New York, 1979.

[19] J. M. Bartunek, "Changing Interpretive Schemes and Organizational Restructuring: The Example of a Religious Order,” Administrative Science Quarterly, Vol. 29, No. 3, 1984, pp. 355-372. doi:10.2307/2393029

[20] A. Schutz, "Collected Papers I: The Problem os Social Reality,” Kluwer Academic Publishers, Dordrecht, 1990.

[21] K. E. Weick, “Sensemaking in Organizations,” Sage Publications, Los Angeles, 1995

[22] K. E. Weick, "Enacted Sensemaking in Crisis Situations," Journal of Management Studies, Vol. 25, No. 4, 1988, pp. 305-317. doi:10.1111/j.1467-6486.1988.tb00039.x

[23] K. E. Weick, “That's Moving-Theories That Matter," Journal of management Inquiry, Vol. 8, No. 2, 1999, pp. 127-133. doi:10.1177/105649269982005

[24] H. Garfinkel, "Studies in Ethnomethodology," Prentice-Hall, Englewood Cliffs, 1967.
[25] G. Morgan and R. Ramirez, "Action Learning: A Holographic Metaphor for Guiding Social Change," Human Relation, Vol. 37, No. 1, 1984, pp. 1-27. doi:10.1177/001872678403700101

[26] P. Singelmann, "Exchange as Symbolic Interaction: Convergences between Two Theoretical Perspectives," American Sociological Review, Vol. 37, 1972, pp. 414-424. doi:10.2307/2093180

[27] A. M. Rose, "A Systematic Summery of Symbolic Interaction Theory,” In: A. Rose, Ed., Human Behavior and Social Processes-An Interactionist Approach, Routledge \& Kegan, Paul, London, 1962.

[28] P. L. Berger and T. Luckmann, "The Social Construction of Reality-A Treatise in the Sociology of Knowledge," Doubleday \& Company, New York, 1966

[29] J. K. Benson, “Organizations: A Dialectical View,” Administrative Science Quarterly, Vol. 22, No. 1, 1977, pp. 1-21. doi:10.2307/2391741

[30] I. Arbnor and B. Bjerke, "Methodology for Creating Business Knowledge,” Sage, Los Angeles, 1997/1981.

[31] D. Sims, S. Fineman and Y. Gabriel, "Organizing and Organizations,” Sage Publications, London, 1993.

[32] A. Schutz, "Reflections on the Problem of Relevance," Yale University Press, New Haven, 1970.

[33] N. Chomsky, "Reflections on Language,” Pantheon Books, New York, 1975.

[34] N. Chomsky, "Rules and Representations," Columbia University Press, New York, 1980.

[35] C. Moustakas, "Phenomenological Research Methods," Sage, Los Angeles, 1994. 